\title{
Experimental Modelling of Autoignition Temperature for Alkyl/Alkenyl Products from Fischer-Tropsch Synthesis
}

\author{
Jan Skřínský1,*, Ján Vereš, and Karel Borovec \\ ${ }^{1}$ Energy Research Centre, VSB-TU Ostrava, 70833 Ostrava - Poruba, Czech Republic
}

\begin{abstract}
Interest in Fischer-Tropsch technology is increasing rapidly. Alkyl/alkenyl products from Fischer-Tropsch synthesis are alternative, renewable, environmentally and economically attractive fuels and there are considered one of the most favorable fuels for conventional fossil-based fuels. The chemistry of this gas-to-liquid industry converts synthesis gas containing carbon monoxide and hydrogen to oxygenated hydrocarbons such as alcohols. The fire hazards associated with the use of these liquid hydrocarbons mixtures are obvious. This article aims to explore the fundamental fire and explosion characteristics for main products composition from Fischer-Tropsch synthesis.
\end{abstract}

\section{Introduction}

\subsection{Interest and challenges}

Nowadays there is a worldwide demand to develop energy efficient and economical processes for sustainable production of alternative chemical compounds and fuels as a substitute for those emerging from petroleum [1]. Autoignition temperature (AIT) is one of the most important variables used to assess fire and explosion hazards of flammable liquids.

It is the lowest temperature at which the test substance will ignite when mixed with air under the conditions defined in the test method. In the industry, it is used for convenient and reliable classification of the flammability of liquids. Investigation of autoignition is always a challenge because AIT depends on several physical-chemical properties, which are discussed in [2].

\subsection{Previous studies}

We realized after a careful bibliographic search autoignition temperature data for methanol, ethanol, propanol, 2-butanol, 1-butanol, and 2-methyl-2,4-pentanediol [3]. These authors soon carried out a re-investigation of the effect of experimental conditions on measuring autoignition temperatures of pure liquid chemicals [4]. In our recent investigation, we identify the effect of experimental conditions on measuring autoignition temperature of

*Corresponding author: jan.skrinsky@vsb.cz 
methanol and ethanol binary mixtures [5]. We have extended the measurement of autoignition temperature of 1-pentanol and its binary mixtures with water [6]. Presented results should provide essential information for the chemicals prepared by Fischer-Tropsch micro catalyst bed avaible at Energy Research Centre, VSB-TU Ostrava and include light hydrocarbons (C1 and C2), olefins, LPG (C3-C4), naphtha (C5-C11), diesel (C12-C20) and $\operatorname{wax}(>\mathrm{C} 20)[7]$.

\section{Experiment}

\subsection{Experimental device}

Experiments were done in the test vessel made by OZM Research s.r.o. and is described in [2]. It generally consists of: 1) mirror mounted above the flask so that the observer may see into the flask without having to be directly over it; 2) insulated cover; 3) electrically heated crucible furnace; 4) aluminium, to promote temperature uniformity; 5) test temperature Chromel-Alumel thermocouple; 6) borosilicate round-bottom, short-necked boiling flask; 7) external thermocouple (bottom); 8) external thermocouple (middle); 9) external thermocouple (top). The photography of the whole system is at Figure 1a and schema is introduced at Figure $1 \mathrm{~b}$.
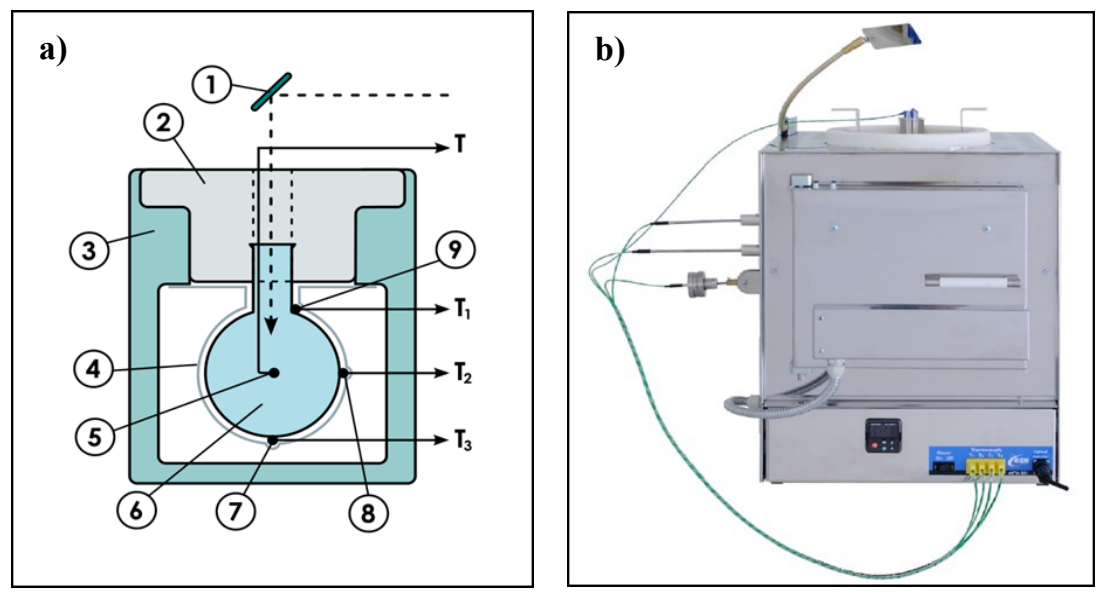

Fig. 1. a) Photography and b) scheme of the autoignition temperature apparatus.

\subsection{Experimental procedure}

The experimental procedure meet the test requirements described by the test method of ASTM E659-78:2005. The amount of substance and the temperature of the test vessel, which is filled with air are varied to find the lowest temperature (of the hot surface) that causes ignition. This standard test method is designed to determine the autoignition temperature of a flammable vapour in air mixture with air at ambient pressure and temperature up to $650{ }^{\circ} \mathrm{C}$. After the internal flask temperature has reached the desired temperature, we have adjusted the temperature controller to maintain this temperature within the designated limits and allow the system to equilibrate. The sample, approximately 50-250 uL, was injected into the uniformly heated flask containing air at a predetermined temperature. After insertion of the sample, the contents of flask were observed in a dark room for $10 \mathrm{~min}$, or until autoignition occurred. 
Autoignition was evidenced by the sudden appearance of a flame inside the flask and by a sharp rise in the temperature of the gas mixture. When the mixture exhibited flames at the preset temperature, the next sample was tested at a lower temperature. These procedures were repeated until the lowest temperature at which the mixture exhibited flames was obtained [5].

\section{Results}

\subsection{Autoignition images}

Figure 2 depicted the occurrence of an autoignition by the sudden appearance of a flame outside the flask following by a sharp rise in the temperature of the gas mixture in Figure 34. The illustrative sample is taken from [5]. The extent of this temperature rise depends upon the difference between the rate of heat generation within the mixture and the rate of heat loss to the chamber walls. The characteristic thermal effects when a combustible liquid is introduced into the chamber at different initial temperatures are illustrated by the timetemperature curves of Figure 4.

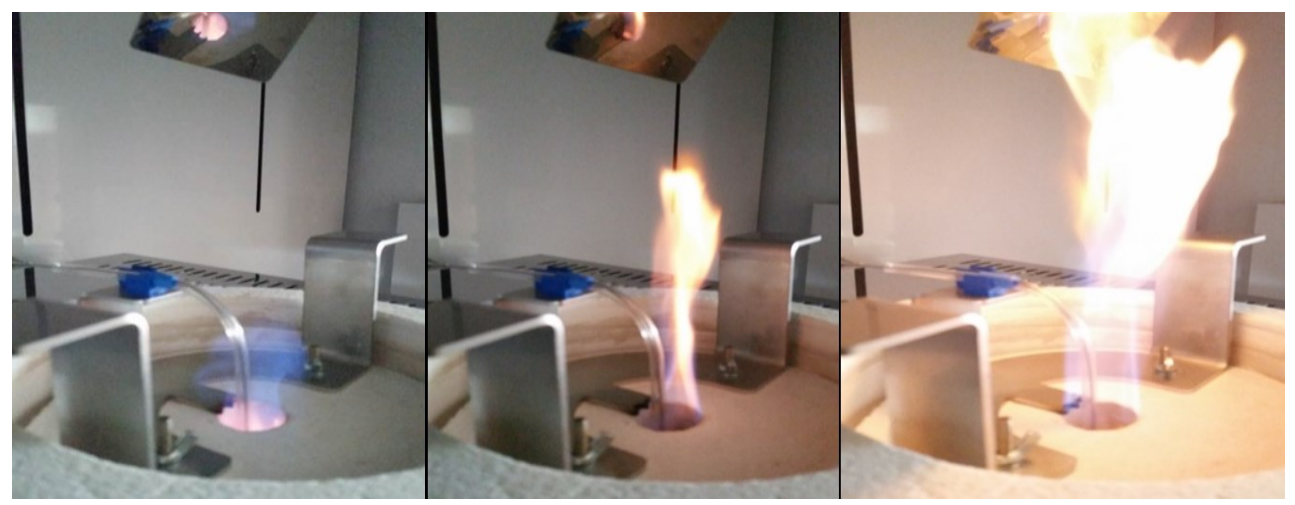

Fig. 2. Development of the flames emitted above the top of the flask $\left(200 \mathrm{ul}, 432{ }^{\circ} \mathrm{C}\right)$.

\subsection{Combustion plots}

According to ASTM E659-78, recorded two values for each test (temperature, ignition delay time). Figure 3 illustrates minimum autoignition temperature for alkyl/alkenyl products from Fischer-Tropsch synthesis that is denoted by the red colour. The measurement of the auto-ignition started according to previous studies (between 440$460{ }^{\circ} \mathrm{C}$ ) that was in the temperature region where our thermometer has its highest sensitivity and where the lowest alcohol has its AIT. The sample to be tested, approximately $100 \mathrm{uL}$, was inserted into a uniformly heated 500-ml glass flask containing air at a predetermined temperature $\left(460^{\circ} \mathrm{C}\right)$. This procedure led to detection of more than 350 identified AIT lines, most of them in the $430-480^{\circ} \mathrm{C}$. At relatively low initial temperatures, there may be further thermal effects. The presented AIT record include the following information: hot-flame selfignition temperature, SIT $\left({ }^{\circ} \mathrm{C}\right)$, ignition temperature, IT $\left({ }^{\circ} \mathrm{C}\right)$, minimum ignition temperature, MIT $\left({ }^{\circ} \mathrm{C}\right)$, slow combustion, SC $\left({ }^{\circ} \mathrm{C}\right)$, and reaction threshold temperature, RTT $\left({ }^{\circ} \mathrm{C}\right)$, for preflame reaction. Figure 4 show the combustion plot of experiments for the alkyl/alkenyl products from Fischer-Tropsch synthesis. In this figure, the $\mathrm{x}$-axis is the ignition delay time between application of heat to a material and its ignition, and the $y$-axis is the preheated temperature of the combustion container. 


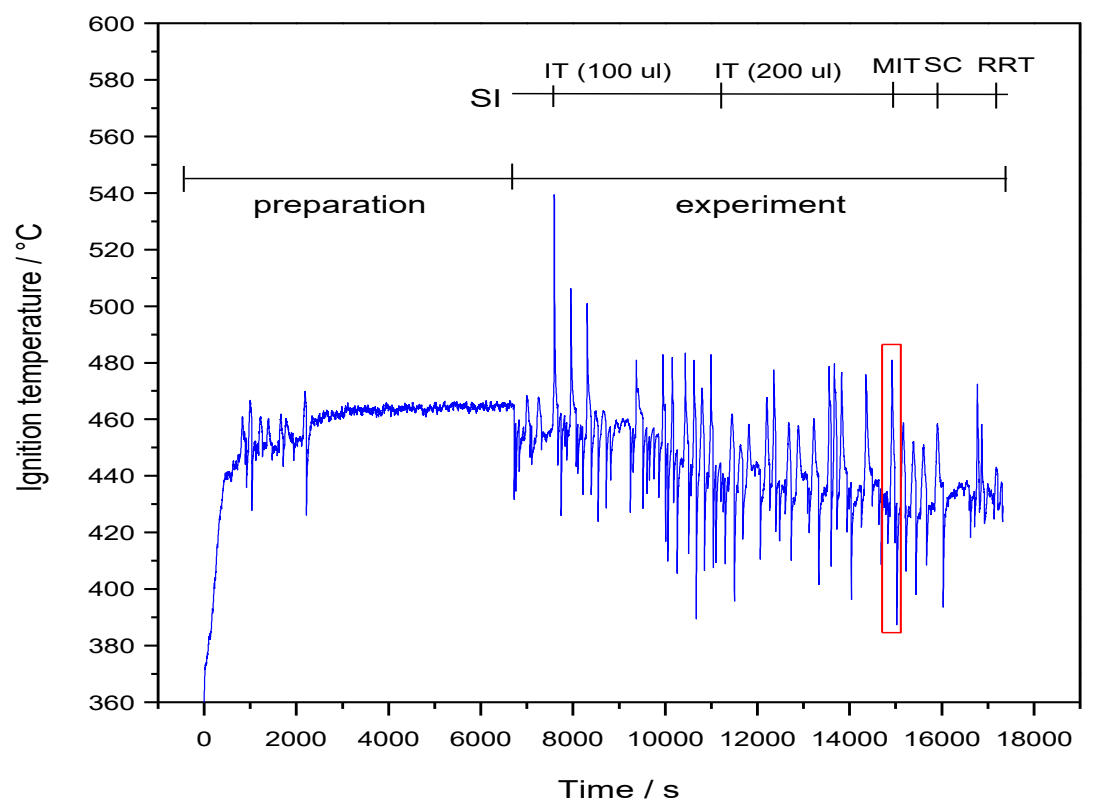

Fig. 3. AIT owing to the alkyl/alkenyl products from Fischer-Tropsch synthesis.

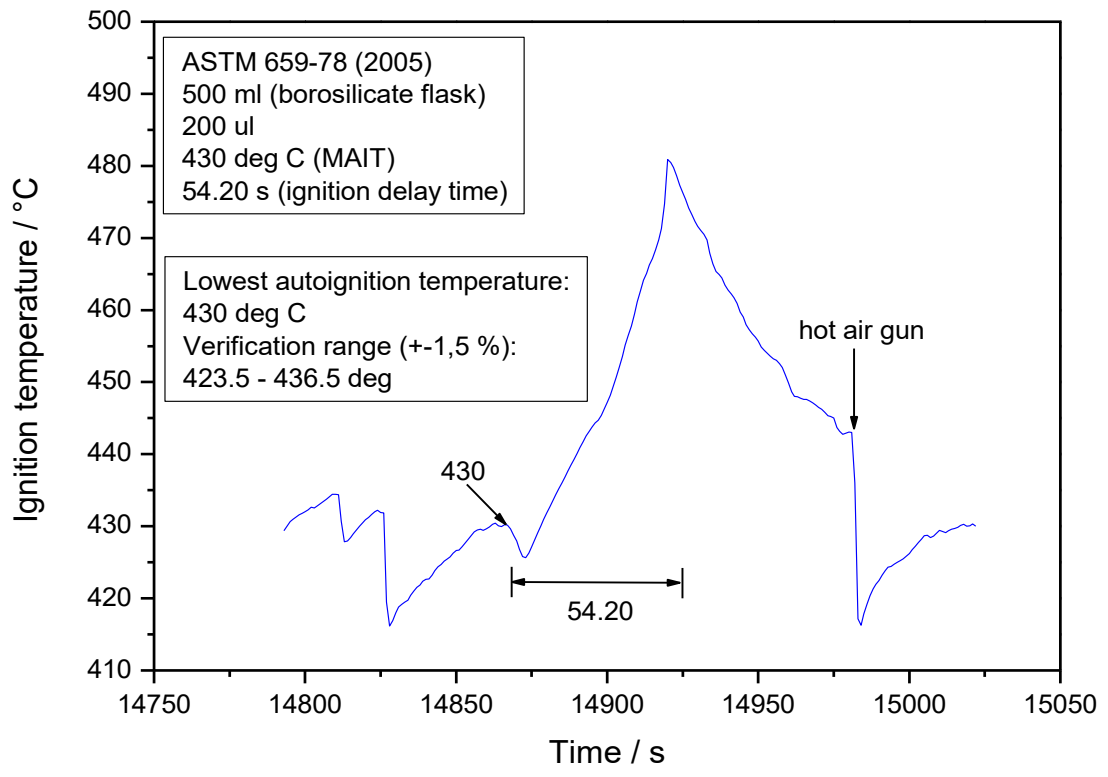

Fig. 4. Example of the AIT time curve with minimum autoginition temperature. 


\section{Conclusion}

In this preliminary study, the AITs of alkyl/alkenyl products has been characterized in the gas phase for the first time. The analysis of the observed records led to identification of more than 350 identified AITs measured in compliance with the ASTM E659-78:2005 test method. An extensive set of autoignition temperatures and ignition delay times have been obtained allowing a systematic comparison between existing standards for open glass flasks to find the reproducible "worst case" value. In the following experiments, these values will be used as approximate initial values for experiments carried out in heated $200 \mathrm{ml}$ flask apparatus to details available information regarding alternative test conditions according to EN 14522:2006.

This work was prepared within the projects: 1) „Innovation for Efficiency and Environment Growth", identification code LO1403 with the financial support from the Ministry of Education, Youth and Sports in the framework of the National Sustainability Programme I and 2) Purification of gas produced by gasification by various materials, method of continuous analysis of ammonia content in ash, identification code SP2018/174.

\section{References}

1. N. Moazami, M.L. Wyszynski, K. Rahbar, A. Tsolakis, H. Mahmoudi, Chemical Engineering Science, 171, 32-60 (2017)

2. ASTM E659-78:2005. Standard Test Method for Autoignition Temperature of Liquid Chemicals. Washington: ASTM Committee E27 (2005)

3. C.C. Chen, H.J. Liaw, C.M. Shu, Y.C. Hsieh, J. Chem. Eng. Data, 55, 5059-5064 (2010)

4. C.C. Chen, Y.C. Hsieh, Ind. Eng. Chem. Res., 49, 5925-5932 (2010)

5. J. Veres, J. Skrinsky, Chemical Engineering Transactions, 52, 1267-1272 (2016)

6. J. Veres, J. Skrinsky, J. Travnickova, A. Dalecka, S. Sevcikova, Chemical Engineering Transactions, 53, 43-48 (2016)

7. M. Wnukowski, Report on the Fischer-Tropsch Micro Catalyst Bed (MCB) operation. Ostrava: 29.08.2017, 26 